Валентина Мойсюк

ORCID: orcid.org/0000-0002-2732-3817

DOI 10.31558/1815-3070.2021.41.14

УДК 811.133 .1 '06-373.7

\title{
ЛИНГВОКОГНИТИВНЫЕ ОСОБЕННОСТИ ВЫБОРА МОТИВАТОРА ФРАЗЕОЛОГИЧЕСКОЙ НОМИНАЦИИ
}

У статті аналізується вибір мотиваційної основи нових фразеономінацій франиузької мови та ступінь довільності / детермінованості иього вибору в аспекті лінгвокогнітивного підходу. Автор доводить, щчо вибір мотиватора зумовлений комунікативною настановою індивіда, особливостями його психіки та аппериептивної бази. Виходячи з теорії ментальних просторів і теорії концептуальної інтеграції, автор показує, щзо в процесі породження нових фразеономінацій індивід поєднує нове знання про об'єкти дійсності з уже наявним у нього досвідом, а покладені в їх основу ознаки асоціативно-смислового характеру визначають різні типи мотиваційного вибору.

Ключові слова: мотивачія, фразеологічна номінація, нова фразеономіначія, довільність / детермінованість вибору, мотиватор, мотиваційна ознака, прототип.

Постановка проблемы и ее актуальность. Современному лингвистическому пространству характерна многовекторность исследований, направленная на когнитивное изучение языка и его культурно-семиотических продуктов, развития и применения речевой способности, реализации в механизмах порождения и восприятия речи в проекции на психическую деятельность человека в его социокультурном взаимодействии и тому подобное. Одной из центральных проблем в плане рассмотрения фактов взаимодействия психических и речевых механизмов выступает анализ мотивационных механизмов, которые на вербальном уровне, по словам Е. Селивановой, «выражаются в структурно-семантических связях между производными и образующими единицами языковой системы», а на когнитивном уровне «являются способом языковой репрезентации концептуальных реляций синергетической системы этносознания» (Селиванова 2008: 156). Исследование мотивации номинативных, в частности фразеологических, единиц объясняет эту систему, проявление психикогнитивных процессов, опосредующих связь языкового и концептуального, процедуры получения, обработки и переработки информации, приобретенной чувственно-эмпирическим путем, внутренней мыслительной рефлексией при взаимодействии с бессознательными процессами. Перманентный интерес современных ученых к изучению лингвокогнитивной системы человека, закономерностей ее формирования, основ мыслительно-речевой деятельности и определяет актуальность нашего исследования.

Анализ исследований проблемы. Впервые понятие мотивации возникло в словообразовании, где оно рассматривалось в формально-структурном и структурно-семантическом аспектах как процесс формирования семантической и формальной связи производного слова с исходным в пределах знакового кода языковой системы (Звегинцев 1973; Потебня 1989; Brekle 1978; Marchand 1960). Позже мотивация попадает в круг проблем теории номинации и, с точки зрения онтологии, истолковывается как способ отражения в производном слове признаков обозначаемого объекта (Голев 1989; Кияк 1988; Кубрякова 1986; Торопцев 1980). И. Торопцев, в частности, трактует мотивацию как «признак слов, по которой носитель языка может говорить об оправданности, рациональности, понятности связи значения и звуковой оболочки в конкретной лексической единице» (Торопцев 1980: 33). Т. Кияк подчеркивает при этом, что «мотивированность зависит не просто от взаимоотношений между формой и содержанием одного знака, но и от связей с другими единицами плана содержания всего языка, поскольку создание каждого нового знака обусловлено достигнутым состоянием всей си- 
стемы» (Кияк 1988: 65). Исходя из этого, ученые изучают мотивацию в двух аспектах: в относительном, выявляя формальную и семантическую связи между словами как знаками, и в абсолютном, устанавливая связи между знаками и их денотатами (Голев 1989: 20). Также говорят о внутренней и внешней мотивации, то есть о предсказуемости структуры и значения производного слова семантикой исходного и словообразовательным формантом (внешняя мотивация), а значение слова - еще и словообразовательной структурой самого производного слова (внутренняя мотивация) (Блинова 2010). В то же время, без внимания остается взаимосвязь и роль знаний, представлений, ощущений, оценки номинаторами в процессе выбора мотивационных основ первичной и вторичной номинации. И даже выделение нового направления в ономасиологии - мотивологии, цель которой в изучении мотивационных отношений в языке в общем, не вывело анализ мотивационных процессов за пределы диады «языковая форма - значение».

Цели и задачи. Следовательно, основной целью нашего исследования является детальный анализ лингвокогнитивных особенностей выбора мотивационной основы новых фразеономинаций современного французского языка, которые поспособствуют пониманию сущности человека и его внутреннего мира в процессе создания единиц вторичной номинации, в частности фразеологизмов. Поставленная цель предусматривает решение следующих задач: определить понятие фразеологической мотивации, установить когнитивные особенности выбора мотиватора новых фразеономинаций современного французского языка, определить степень произвольности / детерминированности этого выбора.

Объект исследования - новые фразеономинации, употребляемые в центральных периодических изданиях современного французского языка; предмет исследования - когнитивные основания выбора мотиватора исследуемых номинаций. Материалом исследования послужила авторская картотека новых фразеономинаций (2200 единиц), отобранных из центральных периодических изданий Франции (Le Figaro, Le Monde, L'Express, L'Observateur и др.) за последние 20 лет и представленных в словаре «Французько-український словник неофразеологізмів» (Гладка 2018).

Методы исследования. Поставленные в исследовании цель и задачи обусловили использование некоторых традиционных лингвистических методов (фразеологическое описание, анализ контекстуального окружения), а также когнитивных теорий порождения смысла. Во-первых, речь идет о разработанной Ж. Фоконье теории ментальных пространств (далее - МП), под которыми он понимает «небольшие концептуальные сферы, сконструированные в процессе мышления и речи с целью локализированного понимания и действия〉 (Fauconnier 1994: 15). Учитывая факт, что в процессе познания мира и коммуникации МП «обрастают» информацией, ученые выделяют три относительно устойчивые сферы, каждая из которых сформирована из нескольких образов познаваемого объекта, а именно: 1) сакральную, в которую входят образы самого человека и мышления, образы социальных и духовных сущностей; 2) профанную, сложившуюся на образах, взятых из мира неосознанной практики и основанных на определенной практической вере, которая позволяет взаимодействовать с миром и верить в его реальность; 3) метафорическую, образы которой связаны с дискурсивным опытом человека и основаны на обеих предыдущих (Бурдье 2001; Козлова 2009; Колмогорова 2006). Образ в этом контексте выступает «посредником между собственно объектом / элементом окружающей среды и языковым знаком во взаимодействии человека с этим миром в языковой коммуникации, описанием прошлого опыта взаимодействия с этим объектом / элементом в вышеупомянутых сферах человеческого бытия, характерного для данного этноса» (Колмогорова 2006: 91).

Во-вторых, в основе нашего исследования лежит теория конщептуальной интеграции, которую Ж. Фоконье и М. Тернер истолковывают как базовую когнитивную операцию, которая осуществляется по определенной схеме на разных уровнях абстракции и имеет четкую структуру (Fauconnier et al. 2002; 2006). Она содержит четыре МП: два исходных МП, порождающее пространство (далее - ПП) и интегрированное пространство (далее - ИП), 
образованное на основе межпространственных связей. Исходные пространства представляют собой независимые друг от друга МП, из которых спроектированы общие для данного момента речевой деятельности образы сначала в ПП, а затем в ИП, где они и формируют новое концептуальное значение (Fauconnier et al. 2006). Именно здесь, в ИП, порождены новые действия, новые концепты, новые эмоции и понимание.

Новизна исследования заключается в том, что в нем впервые предлагается изучить лингвокогнитивные особенности выбора мотивационной основы новых фразеономинаций современного французского языка в рамках когнитивных теорий порождения смысла.

Теоретической значимостью данного исследования есть его вклад в понимание сущности человека и его внутреннего мира в процессе порождения единиц вторичной номинации, в частности фразеономинаций, а практической - возможность применения его результатов в теоретических курсах по когнитивной лингвистике, неологии и фразеологии.

Понятие фразеологической мотивации в современной лингвистике. С переносом вектора исследования языковых явлений с описания на их объяснение растет интерес к мотивации как познавательному процессу, как структуре представления знаний об окружающем мире. Сквозь призму когнитивной науки она получает новое определение, в частности, как «сквозной лингвокогнитивной операции формирования ономасиологической структуры номинативных единиц путем выбора мотиватора (-ов) с мотивированной базы, сформированной исходя из структуры знаний об обозначаемом в сложной системе связей различных познавательных функций этносознания» (Селиванова 2012: 13). Активация таких связей обусловлена «интериоризацией относительно объективных признаков обозначаемого или их ассоциативнообразным, оценочным, парадоксальным восприятием номинаторами» (Селиванова 2000: 153180). Именно такое понимание понятия мотивации послужило теоретическим основанием для выработки собственного подхода к сущности процесса фразеологического семиозиса.

Прежде всего, отметим, что, согласно доминирующей в словообразовании концепции синтаксической природы деривации, ученые абсолютизировали концепцию создания фразеологических единиц (далее - ФЕ) на основе свободных словосочетаний в результате вторичной номинации: генотипы устойчивых словосочетаний, по их мнению, основаны на генотипах соответствующих синтаксических конструкций, переосмысленных в процессе фразеологизации (Жуков 1986). При этом они указывали на «дублетность вторичных номенов», которые сосуществуют с первичными, отличаясь от них семантически, стилистически или функционально (Леснова 1999: 113). Подобное мнение высказывали также в зарубежной лингвистике, где мотивацию трактовали в целом как результат порождения слова из синтаксической структуры, согласно с моделями генеративного синтаксиса (Brekle 1978; Marchand 1960).

С осознанием необходимости объединить результаты исследования в области семасиологии и ономасиологии понимание мотивационных основ фразеологической номинации немного изменилось. Мотивацию истолковывают как «связующую ассоциативно-образную цепочку между денотативным, сигнификативным значением идиомы, ее эмотивной, оценочной, стилистической характеристиками и внутренней формой» (Дубицкая 2011: 2), как «доминирующий, неотъемлемый компонент фразеологического значения, как ассоциативнообразная связь между денотативно-понятийной сферой мотивирующего значения и денотативно-понятийной сферой мотивированного значения ФЕ» (Дмитренко 2012: 109). При формировании непрямых наименований, объясняют исследователи, в переносном смысле актуализируются те признаки, которые являются существенными по содержанию и денотации исходного наименования, что создает условия для предоставления объектам новых, не свойственных им признаков.

Позже повышенный интерес к мотивирующей базе фразеологического значения вызвал смещение вектора исследований от традиционных структурно-семантических особенностей в сторону национально-культурной специфики, обусловленной когнитивными факторами, которые выражаются в различных формах вербализации единиц концептуального 
уровня (Алефиренко 2008; Баранов \& Добровольский 2008; Селиванова 2012). Лингвисты настаивают на том, что фразеологизмы способны транслировать эталоны и стереотипы национальной культуры, концептуализировать не только знания о картине мира, но и все типы отношений субъекта к ее фрагментам и служить таким образом «языковыми экспонентами культурных знаков» (Телия 1996: 250), а также отображать когнитивную сущность языка, поскольку служат проявлением особой внутренней структуры мысли, передаваемой путем особого языкового кода (см. подробнее: (Гладка 2016)).

Говоря о мотивационных основах фразеологической номинации, отметим, что человеческое сознание построено так, что все новое, нетрадиционное провоцирует поиск объяснений, поиск рационального зерна, которое лежит в его основе. Попытка понять непонятное служит основной движущей силой исторического развития личности в частности и общества в целом. Следовательно, вся «познавательно-поисковая активность» человека, по словам С. Панкратовой, носит верификационный характер, направленный на выяснение смысловых вопросов: кто? что? где? когда? куда? зачем? почему? какой? как? сколько? и т.п. (Панкратова 2009: 89). Подобные соображения по поводу человеческого мышления привели ученых к выводу о «смешанном характере» языка «умственных процессов» (Самборская 1994: 8), то есть о существовании довербальных и вербальных этапов умственной деятельности. Характер отображения человеком окружающей среды обусловлен установкой индивида и особенностями его психики и апперцептивной базы. Их специфика заключается в том, что индивид пытается создать мотивированное наименование, которое бы позволило совместить новый опыт с существующим, определить неизвестное через известное, добавить в имеющуюся картину мира новые штрихи и детали.

Исходя из этого, целесообразно рассматривать, вслед за учеными, вторичную непрямую (фразеологическую) номинацию как когнитивный процесс, связанный с созданием нового знания об объектах действительности на основе уже имеющегося опыта взаимодействия с другими и их опознанных признаков и свойств, как «вторичную категоризацию разработанной на первом уровне информации» (Кравченко 1996: 11). Признаки, за которыми выражаются объекты вторичной номинации, имеют, в первую очередь, «ассоциативно-смысловой», внеязыковой характер. Они рождаются не из системно-языковых значений, а из общих знаний о мире. Правильным в этом контексте нам представляется мнение В. Звегинцева, по словам которого когнитивная деятельность человека осуществляется «на уровне смысла», который «вырывает человеческую мысль из плена лингвистических значений (...), способствуя созданию систем знаний над языковыми барьерами, несмотря на то, что эти знания обязательно получают свое объективирующее языковое выражение» (Звегинцев 1973: 178). Именно мотивационный признак обеспечивает связь между понятием об объекте номинации и его вербальным выражением, перекрещивает в сознании индивидуума наглядное и авербальнопонятийное мышление, конструирует не только языковую, но и образную концептуализацию действительности.

Истолковывая внутреннюю форму как «отношение содержания мысли к сознанию», А. Потебня утверждает: «В нашей душе есть богатый содержанием, то есть разнообразными признаками, образ предмета, который и есть неосознанная мысль. Осознание заключается в том, что образ разлагается на признаки, один из которых и становится внутренней формой слова» (Потебня 1989: 97). Интересным представляется также объяснения А. Лосева по поводу рождения внутренней формы слова: «Сначала предмет, который существует объективно, схватывается как таковой, укладывается в акт умозрения, который является общим для всех людей; затем его смысл отрывается от предмета и сравнивается с чем-то иноприродным для данного предмета; поскольку смысл предмета бесконечно разнообразен, то и сравнивать его можно довольно разнообразными способами; затем происходит отождествление смысла предмета с каким-то иноприродным для него смыслом другого предмета, и этот иноприродный смысл становится именем, внутренней формой слова» (Лосев 1995: 193).

Высказанные соображения относительно появления внутренней формы слова вполне 
можно применить к процессу выбора мотивационной основы, или признака, в процессе появления новых фразеономинаций. Ведь порождение нового фразеологизма связано, прежде всего, с мыслительным процессом, первыми этапами которого является наглядно-чувственное восприятие объекта номинации и формирование представления о нем, вследствие чего в сознании человека отражаются и фиксируются особенно выразительные для этого объекта признаки, которые и будут мотивационной основой его номинации. Активация выбранных признаков способствует формированию новых значений, то есть вторичному семиозису. Результатом мотивационного выбора есть определенная когнитивная модель будущей ФЕ, то есть «языковой способ концептуализации и упорядочения реальности, который имеет гибкий, неизменяемый по мере развития человеческого опыта каркас, на который «нанизываются» различные по степени детализации и объема вербальные единицы» (Панкратова 2009: 92). Иными словами, практический опыт, приобретенный индивидом в процессе жизнедеятельности, служит основой выражения структурированных языковых единиц. При переходе к поверхностно-семантическому уровню происходит «оформление» смысла по правилам данного язык, что, по мнению Е. Урысон, означает, что «смысл подстраивается под словарь и грамматику данного языка» (Урысон 1996: 37), происходит отбор необходимых языковых единиц для выражения нужного смысла.

Вопрос о произвольности / детерминированности выбора мотиватора. В контексте проблемы выбора мотивационной основы для будущей вторичной номинации возникает еще один довольно дискуссионный в лингвистике вопрос о произвольности или детерминированности этого выбора. Исследуя процесс номинации, в частности вторичной, исследователи делают вывод об общей ориентации носителей языка на знания близкого, хорошо известного им мира, о релевантности образа, который лежит в основе содержания имени. Важным для выбора имени является наличие в его содержании «салиентных характеристик» (термин С. Харитончик), то есть ярких и особых признаков, которые выделяются в процессе восприятия человеческим сознанием.

Так, В. Огольцев, подробно анализируя сущность устойчивых сочетаний, в частности фразеологических, утверждает, что «признак предмета (А) может быть сопоставим или уподоблен не к какому-нибудь предмету, который имеет одноименный признак, а лишь к такому, для которого он есть характерным (отличным) видовым признаком» (Огольцев 1978: 44). В своих рассуждениях ученый исходит из того, что сравнения представляют собой особый способ, цель и назначение которого заключаются не в выражении понятия, а в выражении восприятия, то есть признака предмета, данного нам ощущением. Сравнительная конструкция формулирует не чувственный образ предмета или явления действительности, а чувственный образ признака предмета. Слово в компаративных структурах «выражает понятие только потому, что оно противопоставляет класс предметов, объединенных общим признаком, другому классу предметов, объединенных другим общим признаком. Поэтому выразить индивидуальный признак предмета означает отделить его от индивидуальных проявлений этого признака в других предметах данного вида. И если индивидуальный признак предмета (А) мы выражаем путем его уподобления одноименному признаку предмета другого вида, то одноименный видовой признак другого предмета сравнительной конструкции (В) должен быть достаточно отграничен от параллельных видовых признаков других предметов данного рода (Огольцев 1978: 42-43).

Подобные суждения нуждаются, на наш взгляд, в определенных уточнениях и замечаниях. Во-первых, в разных ситуациях «салиентными» могут быть различные признаки и свойства объекта номинации для различных номинаторов. К тому же, в своем поиске когнитивных основ для наименования говорящий может выходить за пределы информации, имеющейся в лексическом значении, обращаясь к более широкому диапазону знаний о том, что закреплено за именем - к фоновым знаниям. Так, довольно часто мотивационной основой французских сравнительных коллокаций служит форма, цвет или свойство предметов, окружающих носителей языка в повседневной жизни, например: фp. blanc comme linge «белый как 
полотно», фp. rond comme une balle / une pomme / un æuf «круглый как мяч / яблоко / яйцо», фp. frais comme la rosée «свежий как роса». В этом процессе важную роль играют когнитивные аттракторы, то есть перцептивные, функциональные, поведенческие и др. свойства, которые лежат в основе вторичной номинации. Однако «свойства, входящие в интегрированное пространство [в котором рождается новое фразеологическое значение], могут иметь различный статус в структуре соответствующих значений. Связь обозначаемых именем значений очевиден и легко устанавливаемый прежде всего в том случае, если указанные признаки составляют необходимые и обязательные компоненты лексических значений, как, например, при метонимических переносах» (Харитончик 2009: 418).

Во-вторых, определенная произвольность в выборе мотиватора все же существует. Конечно, трудно согласиться с категоричным мнением Б. Серебренникова, который в своей теории номинации отстаивал тезис о случайности выбора мотивационного признака имени. Он, в частности, утверждал: «Если рассматривать слово с точки зрения лингвистической техники, то чаще всего выбор признака как основы наименований не зависит от каких-либо внешних условий и является результатом чисто случайных ассоциаций» (Серебренников 1977: 115). Однако, выбор мотиваторов детерминирован законами языковой системы, стереотипами этносознания, архетипами коллективного бессознательного, культурными и коммуникативными факторами. Здесь стоит вспомнить слова А. Лосева, который подчеркивал, что в имени сгущена и нагнетена квинтэссенция как человеческого разумного, так и всякого другого человеческого и нечеловеческого, разумного и неразумного бытия и жизни (Лосев 1995). Итак, можно предположить некоторую степень произвольности, а порой и парадоксальности в выборе мотиватора имени, однако в большинстве случаев выбор признака, положенного в основу наименования, детерминирован различными культурно-языковыми факторами. Так, при метонимических переносах имен можем установить использование одних и тех же типов связи (партитивной, поссесивной, локативной, темпоральной и т.д.), или же при метафорических переносах, которые в целом считаются труднее прогнозируемыми вследствие своей многогранности, связи по сходству вкладываются в определенную типологию.

Приведенные выше рассуждения, а также анализ фактического материала позволяют говорить об определенной ступенчатости произвольности / детерминированности выбора мотивационной базы, основанной на статусе выбранного признака для номинации. Благодаря построению интегрированного пространства фразеономинаций современного французского языка нам удалось обнаружить несколько типов мотивационного выбора, а именно:

1) детерминированный выбор, основанный на главных (дифференцированных, непосредственно выраженных) признаках прототипного образа. В процессе порождения новых фразеономинаций они проецируются в ПП и ИП из профанной сферы выходных МП компонентов. В результате формируются номинативные единицы прозрачной семантики, например: фp. raide comme un passe-lacet «очень твердый, крепкий», фр. costaud comme un buffalo «сильный, выносливый», фр. faire des abdos «делать упражнения для пресса; качать пресс», фр. rouler à toc «быстро ехать; мчаться», фр. zéro cerveau «идиот, дурак», фр. ami de boisson «собутыльник», фр. appuyer sur l'accélérateur «подталкивать; поощрять», фр. avaler des kilomètres «долго идти», фр. ouvrir le bal «начать что-то волнующее»;

2) частично детерминированный выбор, основанный на потенциальных (характерных или вероятностных) признаках прототипного образа. Во время создания неологизмов они проецируются в ИП (как правило, через ПП) из метафорической или сакральной сферы выходных МП компонентов словосочетания. Соответственно, образуются номинативные единицы с частично композиционной (частично прозрачной) семантикой, например: фр. être suspendu aux lèvres de qqn «слушать кого-либо с животрепещущим интересом», фр. dose de cheval «сильная доза (о наркотиках)», фр. se tricoter un bas de laine «экономить», фр. avoir la tête ailleurs «быть рассеянным», фр. prendre la tête à qqn «обречь на смерть; убить», фр. faire floc «провалиться (о проекте, планах)», фр. recharger les accus «восстановить силы», фр. se donner de grands airs « хвастаться», фр. allumette sans soufre «слабый человек»; 
3) произвольный выбор, основанный на субъективных, с точки зрения номинатора, признаках прототипного образа. В процессе порождения новых фразеономинаций образы, которые проектируются из исходных МП компонентов, полностью переосмысляются в ИП. Вследствие этого образуется номинативная единица с некомпозиционной (непрозрачной) семантикой, например: фp. habiller la mariée «украшать правду для ее лучшего восприятия», фр. vendre des tapis «спорить, пытаться переубедить», фр. être dans le gaz «ошибаться, делать что-то не так», фр. accrocher un paletot «обманывать», фр. donner dans l'aile «влюбить в себя», фр. avoir un air en coin «лицемерить; притворяться», фр. aller à l'avoine de pharmacie «накачаться наркотиками», фр. aller se faire empailler «быть уволенным», фp. faire l'ane pour avoir $d u$ son «прикидываться глупым ради выгоды». В то же время этот, так сказать, произвольный выбор ограничен, прежде всего, национально-культурными параметрами и особенностями ментального восприятия окружающей среды индивидом, представителем данной этнической общности. Этот факт еще раз доказывает отсутствие абсолютной произвольности в языке и постулирует принцип ее идиоматичности, конвенциональности.

Выводы и перспективы исследования. Подводя общий итог, отметим, что проведенное нами исследование позволяет рассматривать новые фразеономинации как мотивированные единицы, которые опосредствуют связь между языком и опытом, приобретенным чувственно-эмпирическим путем, внутренней мыслительной рефлексией при взаимодействии с бессознательными процессами. Мотивация в этом контексте истолковывается как одна из когнитивных операций семиозиса, которая заключается в выборе мотиватора из фрагмента знаний о обозначаемом, зафиксированного в этносознании, конечным результатом которого является формирование ономасиологической структуры номинативных единиц. Мотивационный выбор фразеологической номинации детерминированный установкой индивида, особенностями его психики и апперцептивной базы. Изучение лингвокогнитивных особенностей выбора этой фразеономинации указывает на детерминированный определенной степенью характер этого выбора со стороны номинатора (в зависимости от того, какие именно признаки концепта сферы ИСТОЧНИКА он видит в денотате, конвенционально подведенном под понятие сферы ЦЕЛИ) и степенью когнитивной выразительности этих признаков (релевантные или значимые, типичные или потенциальные). Собственно поэтому мы считаем целесообразным именно лингвокогнитивный подход к изучению мотивации и мотивационных основ и принципов формирования новых фразеономинаций, благодаря которому мы сможем объяснить характер отображения человеком окружающей среды, особенности его восприятия, фиксации с помощью этих единиц ассоциативно-образных, рационально-мыслительных и даже парадоксальных признаков предметов, явлений окружающей действительности.

В то же время изучение мотивационных основ фразеологической номинации поставило перед нами вопрос детального рассмотрения вторичной фразеологизации, которая по своей природе значительно отличается от первичной: если в последнем случае компонентами фразеономинаций служат слова, которые в процессе фразеологизации переосмысливаются в определенной степени, то в первом - в их основе лежит уже сформированное устойчивое выражение и преобразования претерпевает ее образная семантика в целом. Поэтому, именно в исследовании особенностей мотивационного процесса вторичной фразеологизации и заключается перспектива нашего дальнейшего исследования.

\section{Литература}

Алефиренко, Николай Ф. Фразеология в свете современных лингвистических парадигм. Москва: ООО Изд-во “Элпис”, 2008.

[Alefirenko, Nikolai F. Frazeologiya v svete sovremennyh lingvisticheskih paradigm. Moscow: OOO Izd-vo "Elpis", 2008.]

Баранов, А.Н., Добровольский, Д.О. Аспекты теории фразеологии. Москва: Знак, 2008.

[Baranov, A.N., Dobrovol'skij, D.O. Aspekty teorii frazeologii. Moskow: Znak, 2008.] 
Блинова, Ольга И. Явление мотивации слов. Лексикологический аспект. Москва: Либриком, 2010.

[Blinova, Olga I. Yavlenie motivacii slov. Leksikologicheskij aspekt. Moskow: Librikom, 2010.]

Бурдье, Пьер. Практический смысл / [пер. с франц. А.Т. Бибиков, Е.Д. Вознесенская, С.Н. Зенкин, Н.А. Шматко]. Москва-Санкт-Петербург, 2001.

[Burd'e, Pier. Prakticheskij smysl. Moskow-Sankt-Peterburg, 2001.]

Гладка, Валентина А. «Лінгвокультурологічний підхід у вивченні фразеологізмів французької мови». Науковий вісник Ужггородського університету. Серія: Філологія 1 (35), 2016: 41 46.

[Gladka, Valentyna A. «Lingvokul'turologichnij pidhid u vyvchenni frazeologizmiv francuz'koï movy». Naukovij visnik Uzhgorods'kogo universitetu 1 (35), 2016: 41-46.]

Голев, Николай Д. Динамический аспект лексической мотивации. Томск: Изд-во Алтайского гос. ун-та, 1989.

[Golev, Nikolai D. Dinamicheskij aspekt leksicheskoj motivacii. Tomsk: Izd-vo Altajskogo gos. un-ta, 1989.]

Дмитренко, Олександр П. «Мотиваційні процеси та їх типи у фразеологічному фонді сучасної німецької мови (на матеріалі фразеологічних одиниць соціально-економічної сфери)». Філологічні науки: Наукові записки НДУ ім. М. Гоголя. 2012: 109-114.

[Dmytrenko, Oleksandr P. «Motivacijni procesi ta ïh tipi u frazeologichnomu fondi suchasnoï nimec'koï movi (na materiali frazeologichnih odinic' social'no-ekonomichnoï sferi)». Filologichni nauki: Naukovi zapiski NDU im. M. Gogolya. 2012: 109-114.]

Дубицкая, Елена В. Проблемы мотивации значений идиом русского языка: автореф. дис... канд. филол. наук. 10.02.01. Москва, 2011. <http://dlib.rsl.ru> 23.10.20.

[Dubickaya, Elena V. Problemy motivacii znachenij idiom russkogo yazyka: avtoref. dis. ... kand. filol. nauk. 10.02.01. Moscow. 2011. <http://dlib.rsl.ru> 23.10.20]

Жуков, Влас П. Русская фразеология. Москва: Высш. шк., 1986.

[Zhukov, Vlas P. Russkaya frazeologiya. Moscow: Vyissh. shk., 1986.]

Звегинцев, Владимир А. Язык и лингвистическая теория. М.: Изд-во Москов. ун-та, 1973.

[Zvegincev, Vladimir A. YAzyk i lingvisticheskaya teoriya. Moskow: Izd-vo Moskov. un-ta, 1973.]

Кияк, Тарас Р. Мотивированность лексических единиц (количественные и качественные характеристики). Львов: Вища школа, 1988.

[Kiyak, Taras R. Motivirovannost' leksicheskih edinic (kolichestvennye i kachestvennye harakteristiki). L'vov: Vishcha shkola, 1988.]

Козлова, Наталья Н. Когнитивный механизм метафоризации цвета (на материале фразеологизмов с колоративами green/зеленый): автореф. дис. ... канд. филол. наук: 10.02.19. Иркутск, 2009. <www.islu.ru> 23.10.20.

[Kozlova, Natalia N. Kognitivnyj mehanizm metaforizacii cveta (na materiale frazeologizmov s kolorativami green/zelenyj): avtoref. dis. ... kand. filol. nauk: 10.02.19. Irkutsk, 2009. <www.islu.ru> 23.10.20.]

Колмогорова, Алла В. Языковое значение и речевой смысл: Опыт функционально-семиологического исследования прилагательных-обозначений светлого и темного в современных русском и французском языках. Новокузнецк, 2006.

[Kolmogorova, Alla V. Jazykovoe znachenie i rechevoj smysl: Opyt funkcional'no-semiologicheskogo issledovanija prilagatel'nyh-oboznachenij svetlogo i temnogo v sovremennyh russkom i francuzskom jazykah. Novokuzneck, 2006.]

Кравченко, Александр В. Язык и восприятие: когнитивные аспекты языковой категоризации. Иркутск: Изд-во Иркут. ун-та, 1996.

[Kravchenko, Aleksandr V. Yazyk i vospriyatie: kognitivnye aspekty yazykovoj kategorizacii. Irkutsk: Izd-vo Irkut. un-ta, 1996.]

Кубрякова, Елена С. Номинативный аспект речевой деятельности. Москва: Наука, 1986. 
[Kubryakova, Elens S. Nominativnyj aspekt rechevoj deyatel'nosti. Moscow: Nauka, 1986.]

Лєснова, Валентина В. Номінація людини та іiї рис у східнослобожанських українських говірках: дис.... канд. філол. наук. Київ, 1999.

[Lesnova, Valentyna V. Nominaciya lyudini ta ïi ris u skhidnoslobozhans'kih ukraïns'kih govirkah: dis. ... kand. filol. nauk: 10.02.01. Kiïv. 1999.]

Лосев, Алексей Ф. Форма. Стиль. Выражение. Москва: Мысль, 1995.

[Losev, Aleksey F. Forma. Stil'. Vyrazheniye. Moskva: Mysl', 1995.]

Огольцев, Василий М. Устойчивые сравнения в системе русской фразеологии. Ленинград: Изд-во Ленинг. гос. ун-та, 1978.

[Ogol'cev, Vasiliy M. Ustojchivye sravneniya v sisteme russkoj frazeologii. Leningrad: Izd-vo Lening. gos. un-ta, 1978.]

Панкратова, Светлана А. «Когнитивно-семантические аспекты метафорического моделирования». Известия Российского гос. пед. ун-та им. А.И. Герцена. 2009: 88-99. $<$ https://cyberleninka.ru> 23.10.20.

[Pankratova, Svetlana A. «Kognitivno-semanticheskie aspekty metaforicheskogo modelirovaniya». Izvestiya Rossijskogo gos. ped. un-ta im. A.I. Gercena. 2009: 88-99. $<$ https://cyberleninka.ru> 23.10.20.]

Потебня, Александр А. Слово и миф. Москва: Правда, 1989.

[Potebnya, Aleksandr A. Slovo i mif. Moskva: Pravda, 1989.]

Самборська, Ірина М. Прогностичні особливості внутрішньої форми похідного слова (на матеріалі похідних іменників із загальним значенням “носій звукової ознаки”): автореф. дис. ... канд. філол. наук. Київ, 1994.

[Sambors'ka, Iryna M. Prognostichni osoblivosti vnutrishn'oï formi pohidnogo slova (na materiali pohidnih imennikiv iz zagal'nim znachennyam "nosij zvukovoï oznaki”): avtoref. dis. ... cand. filol. nauk. Kiïv. 1994.]

Селиванова, Елена А. Когнитивная ономасиология. Киев: Фитосоциоцентр, 2000.

[Selivanova, Elena A. Kognitivnaya onomasiologiya. Kiev: Fitosociocentr, 2000.]

Селіванова, Олена О. Сучасна лінгвістика: напрями та проблеми. Полтава: Довкілля-К, 2008.

[Selivanova, Olena O. Suchasna lingvistika: napryami ta problemi. Poltava: Dovkillya-K, 2008.]

Селіванова, Олена О. Світ свідомості в мові. Черкаси: Ю. Чабаненко, 2012.

[Selivanova, Olena O. Svit svidomosti v movi. Cherkasi: YU. Chabanenko, 2012.]

Серебренников, Борис А. Языковая номинация. Виды наименований. Москва: Наука, 1977.

[Serebrennikov, Boris A. Yazykovaya nominaciya. Vidy naimenovanij. Moskva: Nauka, 1977.]

Телия, Вероника Н. Русская фразеология. Семантический, прагматический и лингвокультурологический аспекты. Москва: Школа “Языки русской культуры”, 1996.

[Teliya, Veronika N. Russkaya frazeologiya. Semanticheskij, pragmaticheskij i lingvokul'turologicheskij aspekty. Moskva: Shkola "Yazyki russkoj kul'tury", 1996.]

Торопцев, Иван С. Словопроизводственная модель. Воронеж: Изд-во Воронежского ун-та, 1980.

[Toropcev, Ivan S. Slovoproizvodstvennaya model'. Voronezh: Izd-vo Voronezhskogo un-ta, 1980.]

Урысон, Елена В. «Синтаксическая деривация и “наивная” картина мира». Bопросы языкознания. 1996. № 4: 25-38.

[Uryson, Elena V. «Sintaksicheskaya derivaciya i "naivnaya” kartina mira». Voprosy yazykoznaniya. 1996. 4: 25-38.]

Харитончик, Зинаида А. «О номинативных ресурсах языка, или к дискуссии о концептуальной интеграции». Горизонты современной лингвистики: Традиции и новаторство. Москва: Языки славянских культур, 2009: 412-422.

[Haritonchik, Zinaida A. «O nominativnyh resursah yazyka, ili k diskussii o konceptual'noj integracii». Gorizonty sovremennoj lingvistiki: Tradicii $i$ novatorstvo. Moskva: Yazyki slavyanskih 
kul'tur, 2009: 412-422.]

Brekle, E.H. «Reflections on the Conditions for the Coining Use and Understanding of Nominal Compounds». Proceeding of the 12 $2^{\text {th }}$ International Congress of Linguistic. Innsbruck, 1978: 68-77.

Fauconnier, Gilles. Mental Spaces: Aspects of Meaning Construction in Natural Language. Cambridge, 1994.

Fauconnier, G., Turner, M. The way we think. Conceptual blending and the mind's hidden complexities. New York, 2002.

Fauconnier, G., Turner, M. «Mental Spaces. Conceptual Integration Networks». Cognitive Linguistics: Basic Reading. 2006: 303-371.

Marchand, H. The Categories and Types of Present-day English Word-formation. Wiesbaden: Harrassowitz, 1960.

\section{Источники иллюстративного материала}

Гладка, Валентина. «Неофразеологізація сучасної французької мови: лінгвокогнітивний аспект: монографія: в 2 ч.». Чернівці: Технодрук, 2018. Ч. 2. Французько-український словник неофразеологізмів.

[Gladka, Valentina. Neofrazeologizacia suchasnoï francuz'koï movy: lingvokognityvnyj aspekt: monografia: v 2 ch.». Chernivci: Tekhnodruk, 2018. Ch. 2. Francuz'ko-ukraïns'kyj slovnyk neofrazeologizmiv.]

\section{LINGUOCOGNITIVE FEATURES OF SELECTING A PHRASEOLOGICAL NOMINATION'S MOTIVATOR \\ Valentyna Moisiuk \\ Department of Roman Philology and Translation, Yuriy Fedkovych Chernivtsi National Uni- versity, Chernivtsi, Ukraine}

\section{Abstract}

Background: One of the central problems of cognitive linguistics is the study of the human linguo-cognitive system, the regularities of its formation and the motivational mechanisms during the generation and perception of speech. This study during the generation of phraseological units explains the manifestation of psycho-cognitive processes that mediate the connection between linguistic and conceptual, the procedures for receiving and processing information acquired by the sensory-empirical way, internal mental reflection in the interacting with unconscious processes.

Purpose: The purpose of this study is to analyze the linguo-cognitive features of the selecting of the motivational basis for new phraseonominations of the French.

Results: The phraseonomination is interpreted as a cognitive process associated with the creation of new knowledge about objects of reality based on the existing experience of interaction with others objects and their features. The generation of a new phraseologism is associated with the thought process. Its first stages are visual and sensory perception of the object of the nomination and the formation of an idea about it. Consequently, the features, especially expressive for this object, are reflected and fixed in the individual's consciousness. They will be the motivational basis of the nomination for this object.

The analysis of the French phraseologisms proves a certain degree of arbitrariness / determinism of the selecting of the motivational base. The constructing of the integrated space of phraseonominations helped to distinguish several types of motivational selecting: determinate choice based on differentiated features of the prototype image, partially determinate selecting based on potential features of the prototype image, and arbitrary selecting based on subjective, from the perspective of the nominator, features of the prototype image.

Discussion: The motivation is interpreted as one of the cognitive operations of semiosis, which consists in selecting a motivator from a piece of knowledge about the signified, fixed in ethnic consciousness. Its result is the formation of the onomasiological structure of phraseonomination. 
The motivational selecting of the phraseonomination is determined by the individual's attitude, the peculiarities of his psyche and apperceptive base.

Keywords: motivation, phraseological nomination, new phraseonomination, motivator, motivational feature, arbitrariness of selecting, determinism of selecting, prototype.

\section{Vitae}

Valentyna Moisiuk is Doctor of Philology, Associate professor of Department of Roman Philology and Translation at Yuriy Fedkovych Chernivtsi National University. Her areas of research interests include functional linguistics, cognitive linguistics, neology, phraseology.

Correspondence: hladka_valya@yahoo.fr

Надійшла до редакції 18 березня 2021 року

Рекомендована до друку 1 квітня 2021 року 